\title{
Secas e políticas públicas no semiárido brasileiro: Um debate oportuno acerca do binômio combate a seca $X$ convivência Com o semiárido
}

\section{Droughtand public policies in the brazilian semiarid: an timely debate about the binomy fighting the drought $x$ livelihood with the semiarid}

\section{Sequía y políticas públicas en el semiárido brasileño: un debate oportuno sobre el binomio combate a la sequía $x$ convivencia con el semiárido}

Larissa Ingrid Marques Linhares ${ }^{1}$ https://orcid.org/0000-000191502783 Antônia Vanessa Silva Freire Moraes Ximenes ${ }^{2}$ https://orcid.org/0000-0001-7878-9433 Jander Barbosa Monteiro ${ }^{3}$ https://orcid.org/0000-0003-0086-6923

\footnotetext{
${ }^{1}$ Mestrado Acadêmico em Geografia - MAG- Universidade Estadual Vale do Acaraú (UVA), Sobral, Ceará, Brasil, larissamarkes275@gmail.com

${ }^{2}$ Mestrado Acadêmico em Geografia - MAG da Universidade Estadual Vale do Acaraú-UVA, Sobral, Ceará, Brasil, vanessafxgeo@gmail.com

${ }^{3}$ Mestrado Acadêmico em Geografia da Universidade Estadual Vale do Acaraú-UVA, Sobral, Ceará, Brasil, jander monteiro@uvanet.br
}

Recebido em:03 /08/2021 Aceito para publicação em: 30/09/2021

\section{Resumo}

O artigo objetiva discutir políticas públicas desenvolvidas no semiárido brasileiro, considerando a mudança de paradigma envolta na dualidade combate à seca e convivência com o semiárido. Realizaram-se consultas à bibliografia e sites especializados com informações relacionadas às políticas públicas voltadas à resolução de problemas associados à escassez hídrica e implementadas no semiárido brasileiro em períodos distintos. É perceptível neste vasto território bons exemplos que evidenciam um desenvolvimento pautado em princípios sustentáveis e medidas exitosas adotadas no âmbito da convivência com o semiárido. Os interesses políticos e econômicos não podem se sobrepor à adoção de medidas de convivência com o semiárido. Tratase de uma mudança de paradigma, mas que representa um grande desafio.

Palavras-chave: Políticas Públicas, Semiárido, Seca

Abstract
Geopauta, Vitória da Conquista ISSN: 2594-5033, V. 5, n.3, 2021, e9233
Este é um artigo de acesso aberto sob a licença Creative Commons da CC BY


The article aims to discuss public policies developed in the Brazilian semiarid region, considering the paradigm shift involved in the duality of combating drought and living with the semiarid region. Bibliography and specialized websites were consulted with information related to public policies aimed at solving problems associated with water scarcity and implemented in the Brazilian semiarid region at different periods. Good examples can be seen in this vast territory that show a development based on sustainable principles and successful measures adopted in the context of coexistence with the semiarid region. Political and economic interests cannot override the adoption of measures to coexist with the semiarid region. This is a paradigm shift, but it represents a great challenge.

Keywords: Public policies; Semiarid; Drought.

\section{Resumen}

El artículo tiene como objetivo discutir las políticas públicas desarrolladas en la región semiárida brasileña, considerando el cambio de paradigma envuelto en la dualidad de combatir la sequía y convivir con el semiárido. Se consultaron bibliografías y sitios web especializados con informaciones relacionadas con políticas públicas orientadas a resolver problemas asociados a la escasez de agua e implementadas en la región semiárida brasileña en diferentes períodos. En este vasto territorio se pueden ver buenos ejemplos que muestran un desarrollo basado en principios sostenibles y medidas exitosas adoptadas en el contexto de la convivencia con el semiárido. Los intereses políticos y económicos no se pueden superponer a la adopción de medidas para convivir con la región semiárida. Este es un cambio de paradigma, pero representa un gran desafío.

Palabras clave: Políticas Públicas, Semiárido, Sequía

\section{Introdução}

Ao discorrer sobre a questão hídrica no Nordeste brasileiro, nos deparamos com uma questão intrigante: o Semiárido seria apenas seca, miséria, exaustão e tristeza? A resposta é: não. De fato, a mídia, por muito tempo, se apoiou em sentenças afirmativas dessa natureza e em tantas outras características pejorativas atribuídas ao Semiárido nordestino, onde elas acabaram por favorecer a criação da chamada "Questão Nordeste".

Todavia, neste contexto, surge a seguinte indagação: seria esse pensamento 
LINHARES, L. I. M.; XIMENES, A.V. S. F. M.; MONTEIRO, J. B.

construído a partir da apropriação indevida dos benefícios oriundos de políticas públicas verticalizadas, propostas para esta Região como um todo, e que foram capturadas pelas elites agrárias locais em benefício próprio ou de parentes e apoiadores políticos eleitoreiros, garantindo assim a estrutura de poder e privilégios desses grupos em detrimento do povo em geral, expropriado em suas bases dos bens naturais necessários à sua subsistência, a saber, a terra e a água?

Nesse sentido, destacamos que o Semiárido brasileiro se apresenta como uma das regiões semiáridas do globo que possui os maiores acumulados pluviométricos. No entanto, o problema de escassez hídrica reside em um conjunto de fatores que incluem desde a distribuição hídrica no território e porque não ressaltar a carência de políticas públicas que possam armazenar as águas provenientes do volume precipitado. Ademais, cabe salientar que o alto fotoperíodo, a insolação intra-anual intensa, a predominância do embasamento cristalino (que dificulta a infiltração do volume precipitado), além da alta variabilidade pluviométrica intra-anual e interanual, acabam por interferir no armazenamento superficial e no déficit hídrico da região. Contudo, ainda assim cabe refletir sobre essa condição determinista de que o semiárido é seco e que, por essa razão, o cenário socioeconômico deve permanecer como está.

Como já se sabe, os processos políticos, sociais e econômicos os quais o Nordeste experimentou entre os séculos XIX e XX ocasionou todo um desmantelamento no desenvolvimento mais igualitário da região, conforme Francisco de Oliveira (2008) menciona em sua obra "Elegia para uma Re(li)gião".

Assim, este artigo pretende discutir essa dualidade que envolve o combate à seca e convivência com o semiárido, no intuito de desvelar como se deu esse movimento de mudança de paradigma, além de considerar os distintos momentos históricos e suas influências na implementação de políticas públicas e, possivelmente, o papel que as elites dominantes locais e nacionais acabaram exercendo para promover esse cenário desigual e de escassez. 
LINHARES, L. I. M.; XIMENES, A.V. S. F. M.; MONTEIRO, J. B.

Com o intuito de contemplar tal investigação, foram realizadas consultas a obras à sites especializados, identificando (sempre que possível) políticas públicas desenvolvidas em diferentes períodos históricos. Tais informações foram tabuladas e analisadas adiante.

\section{Desenvolvimento regional: a estruturação das políticas públicas}

A partir do final do século XIX e no decorrer do século XX, as questões envolvendo a problemática da seca tornaram-se visíveis, ou seja, os assuntos relacionados à "problemática regional" e às políticas de assistência do governo, tais como distribuição de cestas básicas, construção de açudes e barragens, entre outros mecanismos de armazenamento de água, começaram a ser discutidas.

Ainda que tais medidas se apresentem, a princípio, como alternativas para contornar os efeitos da escassez hídrica, por outro lado reforçam a centralização do poder, além de possibilitar o desvio de recursos financeiros para os grandes proprietários de terras. Esse grupo de ações acabou recebendo a denominação de “indústria da seca".

De qualquer forma, a construção de um ideal pejorativo e preconceituoso a respeito dos nordestinos ganhou força, pois o que se propagava era uma conotação de pobreza/miséria/desgraça.

Nesta perspectiva, Ferreira (1993) discute sobre o sentido político e econômico que a "indústria da seca" ganhou, a partir, por exemplo, das secas de 1877/1879, 1888/1889, 1903/1904. Assim, segundo a mesma autora, três questões tornam-se evidentes dentro do contexto nacional sobre a seca: o colapso econômico na região, reforçados pelos períodos de estiagem, o interesse da política do Estado priorizando alguns grupos políticos e a outra pautada no interesse político de arrecadação de bens para o Nordeste. Esse território é caracterizado por se apresentar como uma região de quadros climáticos extremos, o conhecido binômio seca-chuva, sendo os efeitos provocados pelas secas um dos maiores passivos sociais do país 
(TRAVASSOS et al., 2013).

A problemática em torno das secas no Brasil é atrelada ao debate político a partir de 1877, quando uma grande seca trienal perdurou até 1879 , juntamente com os primeiros trabalhos das comissões científicas de exploração, esta idealizada entre os anos de 1859 a 1863, onde ocorreram mortes e perdas na lavoura e pecuária, abrindo espaço para as facetas da "Indústria da Seca" (ALMEIDA, 2013).

A Inspetoria de Obras Contra as Secas (IOCS), institucionalizada no ano de 1909, ao citar uma de suas ações na região Nordeste, garantia que:

[...] sempre procurou atingir os males considerados provenientes diretamente das estiagens prolongadas - a falta d'água, o alto índice de mortalidade, a emigração, a crise econômica - através de obras de engenharia, sem levar em conta que esses males são apenas agravados com a falta de chuvas, e que a situação de pobreza e de crise existiriam antes dos períodos de seca (FERREIRA, 1993, p. 127).

Inclusive, a IOCS teve sua nomenclatura modificada em duas ocasiões. Inicialmente, em 1919, quando incluiu o termo "Federal" em sua sigla, denominada, a partir de então, como Inspetoria Federal de Obras Contra as Secas (IFOCS) e, em 1945, quando passou a denominar-se Departamento Nacional de Obra Contra as Secas (DNOCS).

Ainda de acordo com Ferreira (1993), a IOCS teve função primordial de beneficiar principalmente os grandes latifundiários. Os recursos destinados à construção de açudes, ou seja, aqueles que deveriam ajudar os mais necessitados, eram desviados para os donos de terras e, dessa forma, a centralização do poder se tornava cada vez mais forte, enquanto aqueles sertanejos que mais dependiam de tais recursos tornavam-se cada vez mais necessitados.

Tal problemática é evidenciada nas décadas posteriores, com um aumento das desigualdades regionais. Costa (2003), afirma que entre os anos de 1930-1964:

[...] o contraste entre Centro-sul desenvolvido e o Nordeste atrasado fora se estabelecendo e forçando a política de Planejamento destinar "atenção especial" a região. O ponto básico para política de 
LINHARES, L. I. M.; XIMENES, A.V. S. F. M.; MONTEIRO, J. B.

desenvolvimento regional era a seca. Esta se transformou na base ideológica para tal. O debate acerca da "Questão Nordeste" e especificamente da seca, no bojo do ideário do Planejamento Regional, forjavam mudanças estruturais no trato com o Nordeste (COSTA, 2003, p. 65).

Nesse sentido, departamentos como o DNOCS, órgãos como o Banco do Nordeste (BNB) e autarquias como a Superintendência de Desenvolvimento do Nordeste (SUDENE), financiavam as obras do Governo Federal na região nordestina. Enquanto o DNOCS era responsável pela construção de açudes e poços, com intuito principal de contornar o problema de escassez no período de estiagem, o BNB atuava majoritariamente na concessão de crédito individual e apoio às empresas, ajudando no desenvolvimento da região. Já a SUDENE, no final da década de 1950, planejava e coordenava o desenvolvimento industrial (COSTA, 2003).

Gomes (1998) também avalia como o entendimento social está atrelado ao fenômeno da seca. Apesar das características físico-naturais que fazem do Nordeste uma região propensa à ocorrência de estiagens, o fator cultural também exerce influência, de acordo com o autor. Assim, o mesmo afirma que a seca também é um problema cultural. Ou seja, para que esse fenômeno (seca) ganhe tanta visibilidade, existe toda uma logística de trabalho, distribuição de recursos e até mesmo relações sociais.

Inclusive, a seca ainda estabelece um intenso "comércio simbólico", onde a chuva se transforma em abundância e a irregularidade ou ausência desta significa privação, escassez (GOMES, 1998). A oralidade desempenha um papel primordial sobre os horrores da seca, buscando muitas vezes se apoiar na fé para se entender/justificar os acontecimentos que a seca ocasiona.

As representações sociais da seca formam um conjunto organizado de argumentações que satisfazem de alguma forma a necessidade e respostas dos sujeitos sociais que se deparam com o 'fenômeno", e, nesse deparar, aventuram, imaginam, representam formas explicativas com os quais interagem com outros sujeitos, e posicionam-se na sociedade seca (GOMES, 1998, p. 84). 
LINHARES, L. I. M.; XIMENES, A.V. S. F. M.; MONTEIRO, J. B.

Aqui é possível perceber que os motivos/justificativas que procuram desvelar a seca, por vezes apoiam-se em abstrações, onde a figura do divino assume um papel relevante no imaginário do sertanejo. Contudo, independente da seca ser associada ao caráter hidráulico-institucional ou ligada a questões políticas e econômicas, a mesma assume diversos significados, tornando-a como uma espécie de símbolo, o qual pode ser interpretado de diversas formas.

Enquanto uns optariam por compreender a seca como um "castigo divino", onde "Deus" seria o responsável pela ocorrência de tal fenômeno, outros podem acreditar que tal ocorrência seria melhor compreendida a partir da dinâmica da natureza (natura), relacionando-a ao fenômeno hidráulico-climatológico e ao complexo sistema climático que explicaria a escassez de chuva em determinado período. Contudo, há também a vertente que, sem querer menosprezar as anteriores, preferem admitir a seca como um fenômeno social, uma vez que esta possui forte ligação com as políticas desenvolvimentistas da região.

Apoiando-se em tais simbologias, Gomes (1998) afirma que Deus, Natureza e Homem, ou melhor, Religião, Natureza e Sociedade, seriam as palavras que melhor sintetizariam a identificação dos fatores responsáveis pela existência da seca. Campos (2014), afirma que, historicamente, as políticas de combate à seca atuavam como soluções tecnológicas descontextualizadas, sem preocupação com o desenvolvimento da economia local e desprovidas de atenção relacionadas aos saberes e práticas locais.

Considerando as políticas públicas voltadas ao desenvolvimento do Semiárido, é possível considerar que as mesmas giram em torno das próprias vulnerabilidades da região, constituindo assim um fator de reprodução de sua própria condição, ou seja, de acordo com Farias e Pinheiro (2012), as políticas assistenciais acabaram gerando imagens negativas da região e fomentando o conformismo social nas pessoas, através das frentes de emergência ou da construção de barragens, "desenvolvendo" uma constante operação de recriação e adaptação 
LINHARES, L. I. M.; XIMENES, A.V. S. F. M.; MONTEIRO, J. B.

dos mecanismos de dominação e perpetuação da miséria no Nordeste.

Assim, faz-se necessário compreender com bastante criticidade os reais interesses na adoção/implementação de tais políticas públicas, uma vez que estes investimentos apresentam interesses políticos e econômicos associados, em especial quando nos períodos de estiagem, políticos encontram oportunidades de angariar e desviar recursos que podem ser utilizados para outros fins. Ademais, tais situações de emergência ou de calamidade pública também podem figurar como uma oportunidade de "promoção" para aqueles envolvidos direta ou indiretamente na política, uma vez que o "discurso da seca" pode ser utilizado como estratégia, por exemplo, nas narrativas de grupos políticos que procuram cativar e conquistar mais eleitores que acabam se sensibilizando com a causa.

Contudo, nem sempre o oportunismo e interesse político é que marcam tal narrativa. Há que se destacar também um movimento mais recente (em especial, a partir da década de 1980), que procura desmistificar toda essa problemática em torno da seca, a partir da adoção de uma outra terminologia que procura traduzir de maneira mais fiel as políticas públicas hodiernas: a convivência com o semiárido. Afinal, se considerarmos as já mencionadas características físico-naturais do semiárido, sabe-se que as estiagens e secas são recorrentes nesta região do Brasil. Assim, "conviver", "adaptar", "mitigar" são as palavras de ordem, de acordo com essa perspectiva.

Políticas públicas para o semiárido: do discurso do combate à convivência com as secas

Ao se referir ao poder do Estado dentro do contexto da região Nordeste, percebe-se que tais ações são de cunho centralizador, como também divididas de acordo com sua especificidade. Assim, estas ações se solidificaram ao passo em que se criavam órgãos nacionais com o intuito de combater a seca. Infelizmente, tais 
LINHARES, L. I. M.; XIMENES, A.V. S. F. M.; MONTEIRO, J. B.

ações, ao invés de tentar "combater" os efeitos da seca, acabavam por se transformar em disputa de poder de oligarquias vigentes.

As primeiras ações concretizadas voltaram-se, em grande parte, à política de açudagem. Tais açudes, geralmente construídos no interior de latifúndios, eram incorporados ao patrimônio dos latifundiários, oferecendo limitado acesso à água por parte da população mais necessitada. Assim, a construção desses açudes, em vez de possibilitar o acesso à água em abundância para as camadas menos favorecidas, acabavam privilegiando grandes proprietários de terras.

Assim, nota-se que as primeiras tentativas que se concentravam no "combate às secas", foram estruturadas na tentativa de direcionar água ao Semiárido. Além da criação do IOCS em 1909 (atual DNOCS), tais ações procuravam contornar os efeitos provenientes das estiagens prolongadas características da região semiárida, geralmente a partir da realização de obras ligadas direta ou indiretamente ao armazenamento de água (construção de açudes, barragens, poços, estradas etc.).

Apesar da reformulação da IFOCS, transformando-se em DNOCS, Departamento Nacional de Obras Contra as Secas, perpetuaram-se os problemas organizacionais no que se refere à educação, assistência técnica, falta de crédito rural e demais aplicações. Na década de 1950, o DNOCS experimentou novamente um incremento quanto à investimentos durante o governo de Getúlio Vargas, que governou o país de 1951 a 1954. Mas é sob a gestão de Juscelino Kubitschek (1956 a 1961) que se empreendeu ao Nordeste um aspecto voltado à industrialização, com a criação do Grupo de Trabalho para o Desenvolvimento do Nordeste (GTDN), sucedida pela SUDENE.

Todavia, o cenário mudaria a partir da década de 1980, quando as concepções de convivência com o semiárido passaram a ganhar notoriedade. O campo político estava se modificando e novos paradigmas foram surgindo dentro da realidade brasileira. Nesse período, em que as primeiras concepções de desenvolvimento sustentável eram inseridas e a ideia de combate à seca se tornava obsoleta, a nova 
LINHARES, L. I. M.; XIMENES, A.V. S. F. M.; MONTEIRO, J. B.

concepção de convivência com o semiárido ganhava espaço dentro das propostas do Governo Federal para com a região Nordeste.

Tais mudanças, carregadas de suporte técnico e associadas a conhecimentos específicos do semiárido passaram a considerar também a realidade cultural, as potencialidades econômicas e principalmente os aspectos ambientais. Afinal, não é coerente combater algo recorrente e característico da região (do ponto de vista físiconatural da região). Em sua essência, convivência torna-se um termo muito mais adequado, visto que se encontra ligado à ideia de adaptação, lidar com possíveis adversidades, oferecendo mecanismos que permitam que as sociedades respondam positivamente diante de uma situação de seca.

Ademais, cabe mencionar que as políticas de "enfrentamento" à seca evoluíram, de forma que não se deve considerar que uma abordagem exclui a outra, em virtude da imprevisibilidade do fenômeno das secas. Como exemplo, citam-se as cisternas (mecanismo adotado para a convivência com o semiárido/secas), inicialmente implementadas para armazenar águas provenientes das chuvas, mas que hoje também podem armazenar águas oriundas de açudes (pensados a partir da política de "combate" às secas) ou através do transporte em carros pipa (medida emergencial). Assim, nota-se que essa "transição" é melhor compreendida se considerada como transversal às políticas de combate à seca, haja vista o caráter complementar e sinérgico que possuem (MACHADO et. al., 2017).

Um marco importante que representou essa transição foi a repercussão de um documento oficial publicado em 1982 pela Empresa Brasileira de Pesquisa Agropecuária (EMBRAPA) e a Empresa de Assistência Técnica e Extensão Rural (EMATER), intitulado: Convivência do Homem com a Seca. Apesar de ser uma proposta bem preliminar, o objetivo do Governo Federal era discutir alternativas de convivência da sociedade com a seca. De acordo com Silva (2006) a base de ações dos programas do governo se configurava na criação de infraestrutura de captação e armazenamento da água, principalmente para os pequenos agricultores. Com isso, 
LINHARES, L. I. M.; XIMENES, A.V. S. F. M.; MONTEIRO, J. B.

tais ações eram baseadas nas próprias experiências dos nordestinos e instituições atuantes na região.

A partir de então, algumas mudanças começaram a ser implementadas durante as secas de anos posteriores, como a seca de 1992-1993. Tal situação gerou uma série de cobranças para com a atuação do Governo Federal. Por volta de 1993, por exemplo, o movimento sindical rural, associações, cooperativas e organizações não governamentais (ONG's), organizaram um ato público em Recife e ocuparam a sede da Sudene, solicitando providências imediatas para tentar resolver os problemas associados à seca e as ações que buscassem o progresso do Semiárido (SILVA, 2006).

A convivência com o semiárido, em sua essência, foi implementada com intuito de levantar reflexões acerca da mudança na relação sociedade $\mathrm{x}$ natureza, possibilitando uma maior qualidade de vida das famílias através do uso de tecnologias sociais que relacionassem o desenvolvimento econômico com a sustentabilidade ambiental, propiciando uma visão mais aberta das potencialidades e limitações do ambiente semiárido, capazes de desmistificar a ideia de atraso e flagelo social da região (PAIVA; FALCÃO SOBRINHO, 2020).

A criação de alguns mecanismos fortaleceram ainda mais essa nova concepção de convivência com o semiárido, como o Fórum Nordeste que, tendo em sua formação cerca de 300 civis da Região, elaborou um documento denominado "Ações Permanentes para o Desenvolvimento do Nordeste Semiárido Brasileiro", tendo como objetivo central o desenvolvimento da agricultura de subsistência, desenvolvimento sustentável, democratização das políticas públicas, possibilitando dessa forma a (...) "efetiva resistência ao natural fenômeno das secas, com a eliminação das ações emergenciais" (FÓRUM NORDESTE, 1993, p.3)

Assim, o Governo Federal procurou estruturar o Programa de Apoio aos Pequenos Produtores do Nordeste Semiárido, tendo como foco:

Promover um processo permanente e autossustentado de 
LINHARES, L. I. M.; XIMENES, A.V. S. F. M.; MONTEIRO, J. B.

desenvolvimento no meio rural do Nordeste Semiárido, que permita: a) melhorar efetivamente o nível de renda das famílias, até patamares que garantam a segurança alimentar, b) promover o consenso aos serviços básicos, na qualidade e quantidade compatíveis com a dimensão da população rural do Nordeste Semiárido; c) fortalecer o processo de organização da população rural, de modo a efetivar um real exercício da cidadania (FÓRUM NORDESTE, 1993, p.5).

Posteriormente, em meados de 1993/1994, a elaboração do Projeto Áridas trouxe uma proposta de desenvolvimento sustentável para o Nordeste, que tinha como objetivo principal estabelecer o ordenamento da economia e do território semiárido. Assim, algumas novas propostas vieram a somar, incluindo, por exemplo, a ocupação e produção compatíveis com os recursos naturais da região.

É importante destacar que o Projeto Áridas foi influenciado pela Conferência Mundial do Meio Ambiente e Desenvolvimento, ocorrida em 1992 no Brasil. Tal projeto demonstrava preocupação com a natureza e, consequentemente, proporcionar maior qualidade de vida para a população semiárida, ou seja, as medidas apresentadas no documento visavam evitar a sobrecarga ambiental, como também o atendimento das necessidades básicas da população, com a conservação dos recursos naturais, em especial o solo e os recursos hídricos (SILVA, 2006).

Nesse ínterim, já é possível identificar uma certa “(...) valorização de estudos e pesquisas para reduzir a vulnerabilidade e elevar a capacidade de resistência às secas das populações e atividades produtivas no semiárido." (BRASIL, 1959. p. 118)

Passados alguns anos e com a ocorrência de outra importante seca no período de 1998-1999, o Governo Federal também implementou uma nova ação: alfabetizou e capacitou jovens e adultos nas chamadas Frentes Produtivas, além de conceder crédito aos produtores rurais, no chamado Programa Especial de Financiamento para o Combate aos Efeitos da Estiagem. Sobre as ações realizadas neste período, Silva (2006) destaca que:

No primeiro caso, foram direcionados para o Semiárido, programas 
LINHARES, L. I. M.; XIMENES, A.V. S. F. M.; MONTEIRO, J. B.

de alfabetização e de qualificação, favorecendo uma melhor ocupação do tempo dos alistados nas Frentes Produtivas, com o desenvolvimento de suas capacidades humanas. Além disso, foram recuperadas escolas, ampliadas as vagas para o ensino fundamental, e incluída uma nova refeição diária para as crianças matriculadas. Essas ações, sem sombra de dúvida foram fundamentais, mas jamais deveriam ser implementadas apenas emergencialmente no semiárido. No caso do BNB, a intenção era o fortalecimento da infraestrutura hídrica, manutenção do rebanho, com a aquisição de insumos e a formação de reserva estratégica de alimentação animal; e ainda, a produção de alimentos para o consumo humano (SILVA, 2006, p. 80)

A partir de todas essas ações implementadas, é possível perceber seu importante papel sempre que realizadas de forma contínua e não apenas pontual (quando ocorrem apenas nos períodos de secas), figurando assim como verdadeiras medidas mitigadoras, atenuando os efeitos provenientes de secas importantes.

Em 1999, no governo de Fernando Henrique Cardoso, o DNOCS quase foi extinto. Porém, as mobilizações não permitiram que tal fato ocorresse. Inclusive, nos anos posteriores, na gestão de Luís Inácio Lula da Silva, houve um incremento de investimentos no DNOCS.

Ainda no mesmo ano de 1999 e, diante de um cenário preocupante, na Terceira Sessão da Conferência das Nações Unidas para o Combate à Desertificação, os movimentos sociais, igrejas e ONG's propuseram a chamada Declaração do Semiárido, discutindo e divulgando alternativas e possibilidades que versavam sobre a convivência com o semiárido.

O referido documento apresenta um conjunto de propostas baseadas em duas premissas: o uso sustentável dos recursos naturais do semiárido e a quebra do monopólio de acesso à terra, à água e aos outros meios de produção. Segundo Silva (2006), o documento serve de referência como manifesto de constituição da Articulação do Semiárido (ASA), que mobiliza cerca de 700 organizações no Brasil, estando em franca expansão.

Como consequência dessa organização, foi implementado o Programa de 
LINHARES, L. I. M.; XIMENES, A.V. S. F. M.; MONTEIRO, J. B.

Formação e Mobilização Social para Convivência com o Semiárido - Um milhão de

Cisternas Rurais - P1MC. Esse projeto tem como objetivo principal distribuir entre as famílias do semiárido condições de armazenamento de água da chuva voltada para o consumo humano.

Com a sua execução, milhares de famílias foram beneficiadas com água potável, além de capacitação que abordava desde a convivência com o semiárido, até aspectos ligados à cidadania e gênero. A Agenda 21 Brasileira, criada entre os anos de 1997 e 2001, também defendia essa mudança de paradigma.

Entre tantas medidas, na essência, tais mecanismos buscavam:

(...) capacitar o homem do campo para a convivência com a seca, incentivando o uso de tecnologias já comprovadas e difundidas por centro de pesquisas e organização não governamentais como experiência no manejo dos recursos naturais em regiões semiáridas (BRASIL, 2002, p.78)

Nas últimas décadas, o Governo Federal incorporou ideias e conhecimentos associados à sustentabilidade, visando a promoção do desenvolvimento da região semiárida, inclusive abordando e capacitando os sertanejos para conviver com o semiárido, por mais paradoxal que isso possa representar. Afinal, quem mais conhecedor do semiárido que o próprio sertanejo? Esta figura já vem adaptando-se há tempos no semiárido.

De qualquer forma, com o auxílio de pesquisas, da tecnologia e do próprio suporte (seja por meio do conhecimento e/ou políticas públicas), o Governo Federal continuou oportunizando a criação de novos mecanismos, como o Programa Sertão Cidadão: conviver com o semiárido e inclusão social. O objetivo primordial com esse Programa foi a implementação do Sistema de Planejamento e Gestão do Semiárido, ou seja, um sistema que tinha a capacidade de monitorar o espaço semiárido, desde os sistemas ecológicos, até os sociais e econômicos.

Outra estratégia foi a consolidação do Programa de Disseminação de 
LINHARES, L. I. M.; XIMENES, A.V. S. F. M.; MONTEIRO, J. B.

Tecnologias Apropriadas para o Semiárido, buscando investir em tecnologias para mostrar alternativas/possibilidades para a produção de mercado interno e externo.

Instituído em 2003 pelo Governo Federal, o P1MC foi convertido em política pública, com o intuito de atender às famílias de baixa renda residentes em localidades sob influência do semiárido e que possuem dificuldades de acesso à água.

Destaca-se também o Programa Conviver: Desenvolvimento Sustentável, que foi lançado em 2008. A partir desse projeto, o Governo Federal buscou desenvolver o território semiárido, oferecendo condições aos agricultores de melhorar sua qualidade de vida, através de créditos para obtenção e manejo dos recursos hídricos, seguro-safra (renda base), assistência técnica, educação contextualizada com o semiárido, entre outras ações/medidas.

Posteriormente, em 2010, foi criado o Programa Nacional de Universalização do Acesso e Uso da Água - "Água para Todos", tendo como objetivo primordial garantir água aos mais necessitados que residem em regiões com baixos índices pluviométricos. Conforme Campos (2012, p. 285):

No Nordeste Semiárido, em decorrência das adversidades climáticas, que ocasionam grande vulnerabilidade nas fontes hídricas, o programa "Água para Todos" representa uma grande necessidade, mas, também, um grande desafio. As populações difusas que habitam regiões afastadas de rios perenizados e de grandes reservatórios têm em pequenos reservatórios e cisternas suas principais fontes hídricas. Contudo, essas fontes são altamente vulneráveis às secas. No segundo semestre do ano, quando cerca de seis meses são de baixa pluviosidade e de rios com vazões nulas, a maioria das fontes seca. A presença de carros-pipas como fonte de suprimento de águas no segundo semestre tem ocorrido quase todos os anos.

Com a implementação dos Programas P1MC e Água para Todos, a realidade de muitos sertanejos mudou. O acesso à água, inclusive, foi ainda mais oportunizado com a implementação recente (no segundo programa) de cisternas de polietileno, que 
LINHARES, L. I. M.; XIMENES, A.V. S. F. M.; MONTEIRO, J. B.

aceleraram a instalação de tais reservatórios, chegando em 2016 ao número tão desejado de mais de um milhão de cisternas instaladas (MACHADO et. al, 2016).

Observa-se claramente, nos primeiros anos do Governo do Ex-Presidente Luís Inácio Lula da Silva, um incremento considerável de tecnologias sociais de primeira água financiados pelo Governo Federal. Um fator que contribuiu para tal incremento foi a melhoria na comunicação entre o Fórum de Comunidade de Políticas Públicas e o Fórum da Convivência com o Semiárido, com maior fluidez das ideias produzidas neste último (AMORIM; GRISA, 2018).

Independente da concepção adotada (combate à seca ou convivência com o semiárido), é bem verdade que o semiárido brasileiro, historicamente, concentrou inúmeras ações, medidas e mecanismos (em grande parte com o suporte do Governo Federal) com o intuito de contornar (ao menos em sua essência, é o que propõem) os efeitos provenientes da escassez hídrica característica dessa região.

Enquanto que em décadas remotas, a construção de barragens, a escavação de poços, as Frentes de Trabalho e os perímetros irrigados figuravam como aquelas tecnologias e ações que eram implementadas à época para "combater" os efeitos da seca, mais recentemente a transposição de águas entre bacias hidrográficas, a instalação massiva de cisternas, além da implementação de ações que incluem desde a capacitação de agricultores, até a adoção de tecnologias sociais como a cisternacalçadão, cisterna-enxurrada, a barragem subterrânea, tanque de pedra, barreirotrincheira, barraginha, entre outras ações/tecnologias sociais que foram oportunizadas, em grande parte, com o suporte de Programas como o P1MC (Programa Um Milhão de Cisternas) e o P1+2 (Programa Uma Terra e Duas Águas), acabaram por representar mais fielmente a ideia de convivência com o semiárido.

Muitas destas tecnologias sociais foram implementadas nas duas últimas décadas. Ademais, no âmbito da Articulação do Semiárido Brasileiro (ASA), rede que congrega diversas organizações da sociedade civil, o Programa Cisternas nas Escolas e Sementes do Semiárido, também figura como importantes políticas que contribuem 
LINHARES, L. I. M.; XIMENES, A.V. S. F. M.; MONTEIRO, J. B.

para atenuar os efeitos provenientes da seca.

No intuito de melhor apresentar os principais mecanismos, medidas e momentos distintos aqui considerados, as principais ações foram sintetizadas, tabuladas e elencadas na tabela abaixo (Quadro 1). Apesar do esforço em se realizar uma prospecção das ações desenvolvidas em anos mais recentes, observou-se certa dificuldade em acessar informações relacionadas à adoção de políticas públicas voltadas à atenuação dos efeitos das secas.

Quadro 1- Principais ações do Governo Federal de combate/convivência com a seca no Semiárido brasileiro

\begin{tabular}{|c|c|}
\hline Período/ano & Ações implementadas e instituições criadas \\
\hline 1909 & $\begin{array}{l}\text { O Império instituiu uma Comissão Imperial para estudar a abertura de } \\
\text { um canal comunicando as águas do rio Jaguaribe com as do rio São } \\
\text { Francisco, porém foi concretizado e a propriedade foi dada à construção } \\
\text { de açudes e poços tubulares. Em 1904, foram criadas várias comissões: } \\
\text { "Açudes e Irrigação", "Estudos e Obras contra os efeitos das Secas" e de } \\
\text { "Perfuração de Poços". Em 1909, foi instituída a Inspetoria de Obras } \\
\text { Contra as Secas (IOCS), a qual foi transformada em } 1919 \text { Inspetoria } \\
\text { Federal de Obras Contra as Secas (IFOCS). }\end{array}$ \\
\hline 1945 & $\begin{array}{l}\text { O IFOCS foi renomeado para Departamento Nacional de Obras Contra a } \\
\text { Seca (DNOCS). Em } 1948 \text { foi criado a Comissão do Vale do São Francisco } \\
\text { Departamento Nacional de Obras Contra a Seca (DNOCS) concebida } \\
\text { para criar um novo método de gestão de combate as estiagens. }\end{array}$ \\
\hline 1951 & $\begin{array}{l}\text { O Banco Nordeste foi criado em } 1952 \text { para apoiar financeiramente os } \\
\text { municípios que faziam parte do Polígono das Secas. Em 1956, foi criado } \\
\text { o Grupo de trabalho para o Desenvolvimento do Nordeste (GTDN) para } \\
\text { realizar estudos socioeconômicos para o desenvolvimento do Nordeste. }\end{array}$ \\
\hline 1959 & $\begin{array}{l}\text { Neste ano foi criado o Conselho de Desenvolvimento do Nordeste } \\
\text { (CODENO), tendo Celso Furtado como diretor e encarregado de lutar } \\
\text { pela aprovação da SUDENE no Congresso Nacional. Também nesse ano } \\
\text { a SUDENE foi instituída. }\end{array}$ \\
\hline 1970 & $\begin{array}{l}\text { Os programas de desenvolvimento regional passaram a impulsionar a } \\
\text { agricultura no país. Os principais foram: Programa de Integração } \\
\text { Nacional (PIN), o Programa de Redistribuição de Terra e de Estímulo á } \\
\text { Agroindústria do Norte e Nordeste (PROTERA, 1971), incorporados ao I } \\
\text { Plano de Desenvolvimento Nacional (I PND), o Programa Especial para } \\
\text { o Vale do São Francisco (PROVALE, 1972) e o Programa de }\end{array}$ \\
\hline
\end{tabular}


LINHARES, L. I. M.; XIMENES, A.V. S. F. M.; MONTEIRO, J. B.

\begin{tabular}{|c|c|}
\hline & $\begin{array}{l}\text { Desenvolvimento de Terras Integradas do Nordeste - Polo Nordeste } \\
\text { (1974), incorporados ao } 11^{\circ} \text { Plano de Desenvolvimento Nacional (II } \\
\text { PND) }\end{array}$ \\
\hline 1976 & $\begin{array}{l}\text { Foi criado o Projeto Sertanejo que visava tornar a economia mais } \\
\text { resistente aos efeitos da seca pela associação entre agricultura irrigada e } \\
\text { seca. }\end{array}$ \\
\hline 1979- 1983 & $\begin{array}{l}\text { Em } 1979 \text { foi implementado o Programa de Recursos Hídricos do } \\
\text { Nordeste (Prohidro), através de acordo de cooperação com o Banco } \\
\text { Mundial, para aumentar a oferta de recursos hídricos por meio da } \\
\text { construção de açudes públicos e privados e perfuração de poços. Mais } \\
\text { tarde o programa foi renomeado para Pró-água. Em } 1978 \text { foi criada a } \\
\text { Política Nacional de Irrigação que enfatizava a função social da irrigação, } \\
\text { destacando no caso nordestino o combate à pobreza e a resistência à } \\
\text { seca. Em } 1981 \text { foi criado o Programa PROVÁRZEAS, a cargo da } \\
\text { EMATER para prestar assistência ao pequeno agricultor. Em 1984, houve } \\
\text { um acordo entre o Ministério da Integração e o Banco Internacional para } \\
\text { Reconstrução e Desenvolvimento (BIRD) para admitir a implantação de } \\
\text { médias empresas nos projetos de irrigação, podendo ocupar até } 50 \% \text { dos } \\
\text { perímetros. }\end{array}$ \\
\hline 1987 & $\begin{array}{l}\text { O Programa de Irrigação do Nordeste (PROINE,1986) foi estendido para } \\
\text { Programa Nacional de Irrigação (PRONI, 1986). O Projeto Nordeste I } \\
\text { englobou seis programas e vingou apenas o Programa de Apoio ao } \\
\text { Pequeno Produtor Rural (PAPP) do semiárido. }\end{array}$ \\
\hline 1990-1993 & $\begin{array}{l}\text { O Instituto de Pesquisa Econômica Aplicada (IPEA) divulgou o Mapa da } \\
\text { Fome no Brasil (1993). Devido à pressão popular (Movimento Ação da } \\
\text { Cidadania Contra a Fome, Miséria e pela Vida) foi criado o Conselho } \\
\text { Nacional de Segurança Alimentar (CONSEA), que coordenou o } \\
\text { Programa de Distribuição Emergencial de Alimentos (PRODEA, 1993). } \\
\text { Este programa originou o programa Bolsa Renda em } 2001 \text { e o Bolsa } \\
\text { Família em 2004. Nos anos } 90 \text { iniciaram-se os debates sobre os projetos } \\
\text { de assentamento de pequenos produtores versus a participação do } \\
\text { produtor empresário. Em } 1997 \text { foi constituído o modelo de Irrigação com } \\
\text { lotes familiares para projetos de assentamentos e projetos públicos de } \\
\text { irrigação totalmente ocupados por empresas. }\end{array}$ \\
\hline 1998 & $\begin{array}{l}\text { Criação do Programa Federal de Combate aos Efeitos da Seca, } \\
\text { coordenado pela SUDENE, para ajudar aos atingidos pela seca. Em 1998, } \\
\text { o Tribunal de Contas da União (TCU) passou a publicar os resultados } \\
\text { das auditorias de programas sociais. Dentre outros, foram auditados o } \\
\text { Programa Nordeste I SUDENE, para ajudar aos atingidos pela seca. Em } \\
\text { 1998, o Tribunal de Contas da União (TCU) passou a publicar os } \\
\text { resultados das auditorias de Programas sociais. Dentre outros, foram } \\
\text { auditados o Programa Nordeste I (DNOCS e CODEVASF), Pró-água } \\
\text { (DNOCS e SUDENE) e o Programa de Dessalinização Água Boa. Para }\end{array}$ \\
\hline
\end{tabular}


LINHARES, L. I. M.; XIMENES, A.V. S. F. M.; MONTEIRO, J. B.

evitar a desarticulação dos projetos públicos de irrigação, em dezembro de 1999, a SUDENE, SUDAM, DNOCS e CODEVASF foram vinculados ao Ministério da Irrigação (criado em setembro de 1999). Em julho de 1999, foi elaborado pelo Conselho Nacional de Defesa Civil- CONDEC, o Manual para Decretação de Situação de Emergência ou de Estado de Calamidade Pública.

Criação do P1MC - Um Milhão de Cisternas Rurais dentro do Programa de Formação e Mobilização Social para a Convivência com o Semiárido, da ONG ASA- a Articulação do Semiárido, criada em 1999. O P1MC passa a ser Política Pública do Governo Federal, ao ser firmado o Termo

2001- 2006 de Parceria número 001/2003 com o Ministério do Desenvolvimento Social (MDS). Devido as denúncias de corrupção divulgadas pelo TCU, a SUDENE foi extinta em maio de 2001, tendo sido renomeada para Agência de Desenvolvimento do Nordeste - ADENE em junho de 2004. Até 2006, foram construídas mais de 162 mil cisternas, mobilizando cerca de 178 mil famílias, em 1001 municípios.

Criação de programas que intensificavam a permanência do homem do campo em seu lugar originário. Houve permanência e fortalecimento de muitos programas como o Seguro Safra e a criação do Àgua para Todos e do Programa Cisterna nas Escolas. Nesse período também foi criado, pelo Ministério da Integração, o Sistema Integrado de Informações sobre Desastres (S2iD), o qual informatizou todas as informações referentes às 2008-2014 secas/estiagens, desdes os danos em determinadas localidades em virtude da ocorrência de secas, até a solicitação de recursos ao Governo Federal para ações de resposta e recuperação, promovendo assim uma maior transparência e facilitando a comunicação entre as unidades federativas. Observa-se, a partir de 2009, um incremento na implementação de Tecnologias Sociais diversas de convivência com o Semiárido, em especial nos anos de 2011, 2012 e 2013, estes dois últimos considerados como representativos anos de seca.

2015-2016

Observa-se certo declínio na implementação de programas sociais e tecnologias de Convivência com o Semiárido, ainda que esse período represente o ápice de uma importante seca iniciada no ano de 2012.

A implantação de Cisternas no semiárido acabou tornando-se uma política pública cada vez mais descontinuada nesse período. A ASA, juntamente com o Consórcio Nordeste (que reúne governadores e secretários dos Estados nordestinos), passou a arrecadar fundos e 2017-2020 realizar campanhas de mobilização em virtude da redução de repasse de recursos públicos identificado, anos após ano, neste período. Em 2020, no governo do Presidente Jair Messias Bolsonaro, a construção de cisternas obteve o seu menor patamar de investimentos desde a criação do P1MC. O Programa Água Doce (PAD), que em 2011 passou a integrar o Programa Água Para Todos, foi reformulado. O Governo Federal 
LINHARES, L. I. M.; XIMENES, A.V. S. F. M.; MONTEIRO, J. B.

destinou maior atenção ao processo de dessalinização. Iniciada em 2007, a Transposição do Rio São Francisco entra em sua reta final. Nesse período, alguns trechos foram inaugurados, mas nem todos com a capacidade total estimada de operação.

Fonte: Elaborado pelos autores com base em Nascimento (2005); ASA (2021); BRASIL (2021)

Cabe mencionar aqui que, conforme visualizado na tabela anterior, as tecnologias sociais implementadas no semiárido não podem ser descontinuadas. No ano de 2020, a inércia do governo brasileiro quanto à implementação de tais políticas reflete o descaso do mesmo em consolidá-las e disponibilizar mais recursos que oportunizem um maior desenvolvimento e qualidade de vida para as localidades e famílias que necessitam de tal benefício.

O inexpressivo número, por exemplo, de cisternas instaladas no referido ano reflete bem tal desinteresse, quando apenas 8.310 cisternas foram instaladas a partir do Programa P1MC (Um Milhão de Cisternas). Ainda que o contexto de Pandemia tenha exercido um rebatimento sobre esse número, não há como negar a expressiva queda gradual já nos anos anteriores (Gráfico 1).

Gráfico 1 - Número de cisternas construídas com verba federal no período de 2003 a 2020

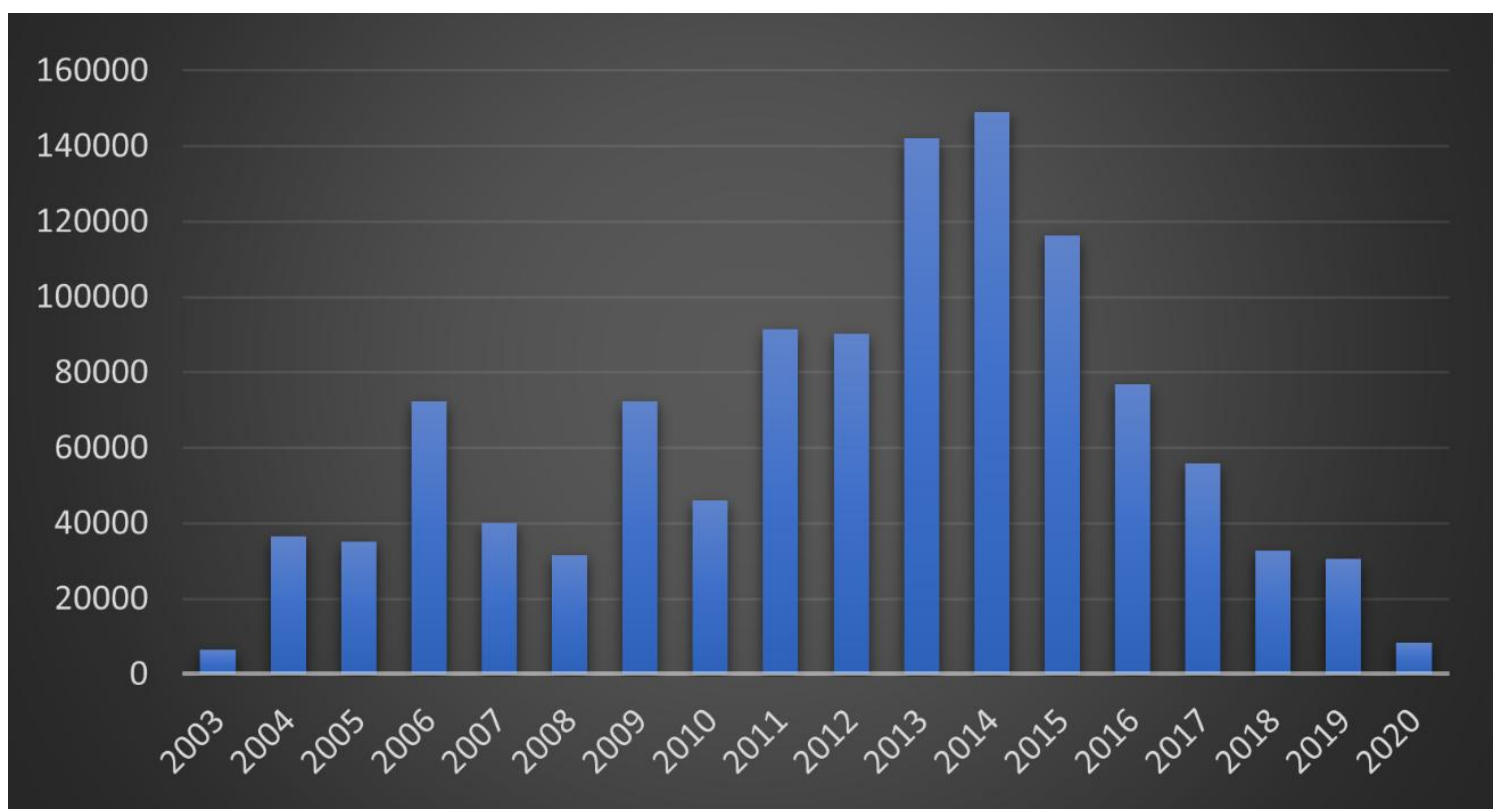

Fonte: Elaborado pelos autores (2021); Baseado em Madeiro (2020); Madeiro (2021) e a partir de informações fornecidas pelo Ministério da Cidadania. 
LINHARES, L. I. M.; XIMENES, A.V. S. F. M.; MONTEIRO, J. B.

De 2014 (ano com o maior número de construções já registradas) até 2020, estima-se que houve um declínio de cerca de 94\% na implementação de cisternas (MADEIRO, 2021). Inclusive, tal política pública, ao invés de cortes e limitação de repasses, deveria receber ainda mais investimentos, visto que o sertanejo necessita de tal tecnologia social para cumprir o isolamento social recomendado pelas autoridades sanitárias no contexto de pandemia.

\section{Considerações finais}

Tal discussão em torno da dualidade de combate à seca e convivência com o semiárido perpassa uma série de outras análises que não se esgotam aqui. De qualquer forma, a partir do que foi exposto, fica claro que o semiárido brasileiro não pode ser visualizado como uma "região problema" ou reduzida a uma "região notadamente seca".

Afinal, diante deste vasto território observam-se bons exemplos que evidenciam um desenvolvimento pautado em princípios sustentáveis que outrora não se imaginava, tais como os diferentes tipos de cisternas implementadas, barragens subterrâneas, entre outros mecanismos de convivência com o semiárido. Trata-se aqui de uma mudança de paradigma e que aponta para um futuro em que mais ações, medidas e mecanismos baseados na convivência com o semiárido sejam experenciados e implementados.

Claro que não há como desconsiderar todo um interesse político/econômico envolto nessa teia de relações que incluem muitos indivíduos e esferas. No entanto, acredita-se que com uma correta atuação do poder público e a organização comunitária, tenhamos um ambiente semiárido mais propício ao desenvolvimento e com maior qualidade de vida.

Espera-se que esse debate seja cada vez mais oportunizado e a implementação de medidas voltadas à convivência com o semiárido fortalecida, pois diante do cenário projetado pelos modelos do Painel Intergovernamental de Mudanças 
LINHARES, L. I. M.; XIMENES, A.V. S. F. M.; MONTEIRO, J. B.

Climáticas (IPCC), que apontam para uma maior intensidade e recorrência de dias secos consecutivos para o semiárido, faz-se necessário voltarmos ainda mais nossas preocupações e ações para esse futuro que não parece muito animador, mas que pode ser contornado com ações bem delineadas e executadas.

Tais políticas públicas carecem de maior atenção e investimentos por parte do Governo Federal. Afinal, nos últimos anos, o que se observa no âmbito da implementação de tecnologias sociais e ações/medidas de convivência com o semiárido é uma política descontinuada, onde os cortes orçamentários e as limitações no repasse de recursos acabam figurando como um entrave para o desenvolvimento social de tais localidades e famílias que eram paulatinamente beneficiadas com os programas do governo.

\section{Referências}

ALBUQUERQUE JUNIOR, D. M. de. A invenção do Nordeste e outras artes. Recife: FJN, Ed. Massangana; São Paulo: Cortez, 1999.

ALMEIDA, V. R. O século do DNOCS. Em pauta: Revista Conviver, Fortaleza, n. 6, p. 55104, 2013.

AMORIM, Lucas Oliveira do; GRISA, Catia. Combater a seca ou conviver com o semiárido? Fóruns e Arenas de Políticas Públicas no Semiárido Brasileiro. Revista Raízes, Campina Grande, v.38, n.2, p.43-57, 2018.

BRASIL. Grupo de trabalho para o desenvolvimento do Nordeste. Uma política de desenvolvimento econômico para o Nordeste. Rio de Janeiro: Departamento de Imprensa Nacional, 1959.

BRASIL. Ministério do Meio Ambiente. Avaliação e ações prioritárias para a conservação da biodiversidade da caatinga. Brasília: MMA, 2002.

CAMPOS, J. N. B. A evolução das políticas públicas no Nordeste. In: MAGALHÃES, A. R. A questão da água no Nordeste. Brasília: CGEE, 2012. p.261-87.

CAMPOS, J. N. B. Secas e políticas públicas no semiárido: ideias, pensadores e períodos. Revista Estudos Avançados, v. 28, n. 82, 2014.

COSTA, José Jonas Duarte da. Impactos Socioambientais das Políticas de Combate à Seca na Paraíba. Tese (Doutorado em História Econômica), Faculdade de Filosofia, Letras e Ciências Humanas. São Paulo-SP, 2003.

FARIAS, Ana Elizabete Moreira de; PINHEIRO, Josefa Nunes. do Combate a seca À 
LINHARES, L. I. M.; XIMENES, A.V. S. F. M.; MONTEIRO, J. B.

Convivência com o Semiárido: (Re) Significando a Politica para os "Nordestes". Semiárido: Estados, Politicas, Públicas E Saúde. 74. Ed. Sobral: Edições Universitárias, 2012. v. 14, cap. 5, p. 99-119. ISBN 978-85-89888-74-5.

FERREIRA, L. F. G. Raízes da indústria da seca: o caso da Paraíba. João Pessoa: Editora Universitária/UFPB. 1993

FÓRUM NORDESTE. Ações permanentes para o desenvolvimento do Nordeste semiárido brasileiro: proposta da sociedade civil. Recife: Contag: Assocene, 1993.

GOMES, Alfredo Macedo. Imaginário social da seca. Recife: FUNDAJ, Editora Massangana, 1998.

LINHARES, Larissa Ingrid Marques. Do combate à seca a convivência com o semiárido: um estudo de caso no distrito de caracará, sobral, ceará. Anais... I CONIMAS e III CONIDIS. Campina Grande: Realize Editora, 2019. Disponível em:

$<$ http://www.editorarealize.com.br/artigo/visualizar/63454>. Acesso em: 10/06/2021.

MACHADO, Tayasa Tamara Viana; DIAS, Jobson Targino; SILVA, Tarciso Cabral da.

Evolução e avaliação das Políticas Públicas para atenuação dos efeitos da seca no semiárido brasileiro. Gaia Scientia, v.11, p.84-103, João Pessoa, 2017.

MADEIRO, Carlos. Maior programa para armazenar água no sertão tem queda de $94 \%$ em seis anos. UOL Notícias, São Paulo, 04 fev. 2021. Disponível em:

https://noticias.uol.com.br/cotidiano/ultimas-noticias/2021/02/04/cisternas-sertao-nordestequeda.htm. Acesso em: 05 jul. 2021.

MADEIRO, Carlos. Sob Bolsonaro, programa construiu menor número de cisternas de sua história. UOL Notícias, São Paulo, 12 fev. 2020. Disponível em:

https:/noticias.uol.com.br/politica/ultimas-noticias/2020/02/12/bolsonaro-menor-numerocisternas-desde-origem-programa.htm. Acesso em: 05 jul. 2021.

OLIVEIRA, Francisco de. Elegia para uma re(li)gião: Sudene, Nordeste. Planejamento e conflito de classes. São Paulo: Boitempo, 2008.

PAIVA, Ana Mesquita; FALCÃO SOBRINHO, José Falcão. Do combate à seca à convivência com o semiárido. Revista Homem, Espaço e Tempo, n.3, v.14, p.109-126, Sobral, 2020.

SILVA, Roberto Marinho Alves da. Entre o combate à seca e a convivência com o semiárido: transições paradigmáticas e sustentabilidade do desenvolvimento. Tese (Doutorado em Desenvolvimento sustentável). Programa de Pós-Graduação em Desenvolvimento Sustentável. Universidade de Brasília, Brasília - DF, 2006, 298p.

TRAVASSOS, I. S.; SOUZA, B. I.; SILVA, A. B. Secas, desertificação e políticas públicas no semiárido nordestino brasileiro. Revista Okara: Geografia em Debate, v. 7, n. 1, p. 147-164, João Pessoa, 2013. 
LINHARES, L. I. M.; XIMENES, A.V. S. F. M.; MONTEIRO, J. B.

Contribuição dos autores:

Autor 1 - Produção Textual e Tabulação das principais ações/políticas públicas de convivência com o semiárido.

Autor 2- Revisão Textual e discussão acerca da estruturação das políticas públicas no semiárido.

Autor 3- Revisão do texto, formatação, produção de conteúdo gráfico e sistematização de informações referente às políticas públicas implementadas no semiárido. 